\title{
The Development of Students' Creative Ability in Mechanisms and Machine Theory Course
}

\author{
Yue Liu \\ School of Mechanical and Electrical Engineering \\ Changchun University of Science and Technology \\ Changchun, China \\ liuyue@cust.edu.cn
}

\author{
Kaidi Yu \\ School of Mechanical and Electrical Engineering \\ Changchun University of Science and Technology \\ Changchun, China \\ yukaidi@cust.edu.cn
}

\begin{abstract}
Mechanisms and machine theory is an important course which cultivates students' ability of creative design, system design and concept design. The design scheme about mechanical movement is the most creative content in mechanical engineering design, which plays a very important role in cultivating students' creative design ability. In the teaching process, according to the process of the cultivation of creative thinking, using advanced modern design method to guide the student to realize the concept and structure design, make the students give full play to the creative thinking, and lay a solid foundation for training creative and practical talents.
\end{abstract}

Keywords-creative ability; mechanisms and machine theory; teaching

\section{INTRODUCTION}

Cultivating and improving students' creative thinking ability is an important task in higher school education reform $[1,2]$. In the teaching link of enginery profession, mechanisms and machine theory is an important link of training students' creative thinking and creative ability. In the course of mechanisms and machine theory, the design scheme about mechanical motion is the most creative content in mechanical engineering, which plays a very important role in cultivating students' creative design ability. Mechanisms and machine theory not only teaches foundation and professional knowledge to students, but also cultivates students' analysis and the ability to solve practical problems $[3,4]$. At present, in the teaching link of mechanisms and machine theory course and course design, for many years students use knowledge to passive imitate to complete teacher's proposition. Although there is probably a little innovation in the design, but because of the lack of mastery and application of the advanced modern design method, the systematic training of the students' creative thinking ability is in the largely limited, lead to students lack of awareness of innovation, after getting a job, they can't to adapt themselves to the high demand of the actual work, can't to adapt the new trend and new features of development of science and technology, hard to cultivate the talent who can dominated the fierce international competition in the new century. In this kind of situation, according to the cultivation process of creative thinking, this paper puts forward some ideas about creative thinking ability training in mechanisms and machine theory course, which effectively guide the student to actively carry out creative design and cultivate the students' creative thinking.

\section{Cultivation of Creative Thinking In the Teaching PROCESS}

For sophomore, they have already mastered the basic knowledge of relevant major, but they lack the integration and application of these knowledge, at the same time also lack of experience. If in the mechanisms and machine theory course teaching, the teachers can use their actual experience, and according to the law of forming creative thinking, arouse the students' creative inspiration, show them how to use creative design method to do creative design, to make them have creative thinking ability, to build a bridge for learning professional courses and cultivating innovative talents.

The cultivation of students' creative thinking reflects in the following respects:

\section{A. Cultivation of Imaginal Thinking}

Knowledge development is a continuous circulation process which contains old knowledge, innovation and new knowledge [5]. So, teachers must constantly provide new knowledge, enable students to seek a variety of methods to solve the problems, and make the concepts into system. In the mechanisms and machine theory teaching activities, many of the concepts and theories teaching need to resort to the thinking in images, to guide the students to understand and grasp some concepts and theories. By thinking in images in organization teaching activities, you might get to touch the twice the results with half the effort. If students don't have this aspect of perceptual knowledge, such as the mechanical structure, movement transmission, working principles and so on, it's hard to imagine the movement and force transmission. If use of visual aids or multimedia courseware, those not only can inspire students' positive thinking, but also enrich the students for the imagination of this problem, so that the students can grasp these concepts thoroughly. For example, in the explanation of the evolution of the planar linkage mechanism, through the transformation of different toggle to demonstrate by animation, students can be very easy to associate to the up and down of dump car, engine crank-link mechanism and so on, and put forward their own views and ideas. Its effect is often beyond the teacher's vision. Thus students' creative ability and desire to learn are motivated effectively. 


\section{B. Cultivation of Different Thinking}

To cultivate the students' different thinking, we have to change the traditional teaching mode and create a highly free thinking space. Not only allow students to question teachers and books, but also allow students to have inspiration and create its own thing. Teachers should be good at discovering reasonable factor of different thinking, stimulating the students' innovation psychology, cultivating the innovative consciousness. Due to the diversity of the institution, teachers will let all sorts of design plan in public; let them compare with each other, point out the advantages and disadvantages in order to choose the best scheme. Reverse thinking is commonly way of creative thinking. Some problems are difficult to break through, but thinking its opposite often received an unexpected result.

\section{Cultivation of Divergent Cultivation}

Divergent thinking is the foundation of cultivating students' space imagination. It is also the important part of creative thinking. It is a thinking method which seeking answers from several aspects in the situation of given condition and inadequate data [6]. In the divergent thinking training, students are required to catch the essence of the problem, draw inferences about other cases from one instance, carry out creative thinking and give the best solutions to the problems.

The overall creative process is from dispersive thinking to focus thinking and return to dispersive thinking. To cultivate dispersive thinking, at the same time, we should cultivate the focus thinking and the ability of abstract, summarize, judge and reasoning. In mechanisms and machine theory course, teachers let students to learn to collect the information of solving problems from many sides and multi-channel, and expand the thinking of problem solution, make full use of external information to associate. Teachers should guide the students to find the entrance of thinking through the lateral contact and lengthways contact of knowledge.

\section{Training of Creative Quality in Teaching Process}

\section{A. Determining Teaching Goals for Cultivating Students' Creative Quality}

Mechanisms and machine theory is a professional technology basic course of machinery major, it is a more integrated application design course. According to the characteristics of the course and teaching goal orientation, reflecting the students as the main body of the teaching principle, mobilizing students' learning initiative, designing reasonable lesson plan and teaching content, not only pay attention to the systematic knowledge, but also not be limited by program, pay attention to the function of the guidance of the teaching objectives, cultivating the students' creative thinking quality. When teaching in class, teach the concept, definition and method in easy-to-read formats and lively and interesting language to create an atmosphere with genuine interest. For example: when teaching link mechanism, you can put the manipulator, car door and umbrella as example, not only make students get knowledge satisfactorily, but also can make concept of teaching and method statement lively and clear, give students a unforgettable impression, inspire the students' creative thinking. In the fourth national college students mechanical creative design contest, our students designed a model----the rescue machine for deep hole, which adopted an umbrella mechanism as the support institutions of manipulator. The model won the first prize, and has been applied for the invention patent.

\section{B. Optimizing the Teaching Method For Cultivating Students' Creative Quality}

Optimizing the teaching method is to express the teacher's leading role. Under the teacher' guide, the students' creative potential is expressed and their creative thinking is cultivated. In the process of teaching, not only pay attention to the teaching of basic theory, but also analysis in combination with the production examples. Linking theory with practice, the teacher' stand-up situation is changed. In teaching typical mechanisms, contacting specific case of daily life, such as crusher, sewing machine, mend shoes machine to analysis. The content what teacher speaks is visible and tangible, closely related to the daily life, so that students could master linkage mechanism and cam mechanism which applied in the machines quickly. It is beneficial to the development of the students' imagination, observation and creative thinking. This optimizing method fully mobilizes students' subjective initiative of learning, extends the students' space of perception. Some practical problems could be solved by discussion. We can use classroom discussion method, so that students would have positive thinking and heated discussion, which not only make the atmosphere active, but also learn knowledge. Obviously, optimize the teaching method plays an important role in the training of thinking quality and creative thinking quality.

\section{Strengthening the Practice Teaching For Cultivating Students' Creative Quality}

Practice teaching plays an important role in knowledge acquisition, the formation of the ability and development. The education combined theory with practice transforms the theory knowledge to practical ability, and it is beneficial to the training of students' creative. In the mechanical theory course teaching, we need to create conditions so that students will contact more actual production. For example: visiting laboratory showroom, factory workshop, opening experimental, carrying on the electronic teaching, organizing field teaching, encouraging students to participate in various professional competition and so on, continuously accumulating practical knowledge, to stimulate the thirst for knowledge. Through the special research practice activity will help students to understand and consolidate theory knowledge, so that students will think problems in the practical teaching, solve problems of practical and life and enhance the ability for using knowledge, stimulate students' scientific research innovation ability. 


\section{Forming Innovation Team for Cultivating Students' Creative Quality}

Make full use of students' after school time, according to the student's specialty and interest to form innovation team. Implementing tutorial system, the teacher give design theme, with a term for cycle, submitting results in the way of big homework, through the project survey and scheme comparison, it is the best to form virtual prototype. This innovation team not only can make students innovate day-today work, improve the knowledge comprehensive application, but also lay a foundation of theoretical and practical of all kinds of professional skills. In recent years, the school carries out innovation experimental project activities, selects the students of solid theoretical and strong practical ability, and equipped with teachers. If the project is formal approval, the school will give some project funds to provide funds guarantee for students' innovation practice activity, which can mobilize the enthusiasm of participating in innovative activities, cultivate the students' rigorous study style, cooperation spirit and creative ability.

\section{EFFECT OF CREATIVE DEsign IN Practice}

In recent years, according to the above process and the standard guidance is given for students, we have the obvious effect. Mainly displays in the following respects:

Our students has taken part in the national college students mechanical creative contest for four times, they have won 9 first prize, 12 second prize.

According to the content of the course design of Mechanisms and machine theory, draw up subjects, such as sorting machine tool, drinks filling machine, automatic pressure piece of moulding machine. Building innovation team lets the students to give full play to the team cooperation spirit, using innovative design method, completing solutions of the principle structure scheme design.

In the process of the guidance of the title, according to process of develop the ability of innovation, make the innovation ability of students improved greatly. The survey of the students' professional class and graduation design show that the creative ability plays a very important role in the enhancement of productive capacity in Mechanisms and machine theory course.

\section{CONCLUSIONS}

To cultivate the students' mechanical creative thinking skills, not only pay attention to the cultivation of a way of thinking, but also pay attention to the combination of all kinds of thinking mode, forms the scientific thinking structure, grasps the creative methods, and constantly improve the creative ability. In the process of course design of Mechanisms and machine theory, we should let the student fully understand that innovation is not unattainable. As long as they have abundant knowledge and experiences, set up high innovation spirit and have a healthy psychological quality, apply science and skilled modern design method, the creative ability will become their advantage weapons; make them stand in the leading ranks in working competition and technological innovation in the future.

\section{REFERENCES}

[1] Lou Jianguo. "Mechanisms and machine theory course design teaching exploration and practice.” Journal of Shaoxing University (Natural Science). vol. 23, pp.114-116, August 2003.

[2] Lu Yueli, Zhang Mingcheng, Xiong Bingsheng. "Strengthening exploration of cultivating innovation skills in mechanisms and machine theory course design." Guangxi Machinery. pp.40-42, March 1998.

[3] Wang Ping, Shen Xiaoyang. "Mechanical engineering machinery foundation series practice teaching reform of the course." Journal of College Education Technology. vol. 24, pp. 57-58, February 2005.

[4] He Guoqi, Hu Chengwu,Wu Jiping. "Mechanical principle in the course design of training students' innovative ability exploration.” Journal of Zhuzhou engineering. vol. 20, pp. 145-146, June 2006.

[5] Zhang Meilin. Mechanical Create Design ,Beijing: Chemical Industry Press, 2005

[6] Yang Jiajun. Mechanical system innovation design, Wuhan: Huazhong university of science and technology press, 2006 